\title{
Kinetic Models of Integrated Solidification and Cementation of Cement- formation Interface with New Method
}

\author{
Jun Gu*, Pei Zhong, Wenzheng Qin, Haoya Liu, Lifei Dong and Yijun Yang
}

Petroleum Engineering Department, Faculty of Earth Resources, China University of Geosciences, Wuhan 430074, China

\begin{abstract}
The isolation failure of cement-formation interface is an important and urgent problem in oil production, while an effective way to solve it is to realize the integrated solidification and cementation of cement-formation interface (ISCCFI). In order to study the kinetics of ISCCFI with MTA (Mud Cake to Agglomerated Cake) method, the Diamond Differential Scanning Calorimetry Analyzer is adopted for experiments with dynamic method and isothermal method. The results show that there is a linear relationship between the solidification reaction temperature and the heating rate of ISCCFI with MTA method. For the first exothermic peak, the initial temperature, peak tip temperature and final temperature are $53{ }^{\circ} \mathrm{C}, 69{ }^{\circ} \mathrm{C}$ and $83{ }^{\circ} \mathrm{C}$ respectively, and the apparent activation energy of solidification reaction is $44.39 \times 10^{-3} \mathrm{~kJ} \cdot \mathrm{mol}^{-1}$, the natural logarithm of preexponential factor is 7.26 , the solidification reaction order is 0.88 . For the second exothermic peak, the initial temperature, peak tip temperature and final temperature are $83^{\circ} \mathrm{C}, 92^{\circ} \mathrm{C}$ and $114{ }^{\circ} \mathrm{C}$ respectively, and the apparent activation energy of solidification reaction is $99.14 \times 10^{-3} \mathrm{~kJ} \cdot \mathrm{mol}^{-1}$, the natural logarithm of preexponential factor is 24.77 , the solidification reaction order is 0.94 . The maximum solidification reaction rates at $50{ }^{\circ} \mathrm{C}, 75^{\circ} \mathrm{C}$ and $90{ }^{\circ} \mathrm{C}$ are $0.09 \times 10^{-3} \mathrm{~s}^{-1}, 0.27 \times 10^{-3} \mathrm{~s}^{-1}$ and $0.51 \times 10^{-3} \mathrm{~s}^{-1}$ respectively. The kinetic models of ISCCFI with MTA method under different temperatures are established. It provides a theoretical and technical support for the isolation improvement of cement-formation interface.
\end{abstract}

Keywords: Kinetic model, Fluid channeling, Cement-formation interface, MTA method.

\section{INTRODUCTION}

Along with the secondary development of old oilfields, the oilfield development in China and even the world mainly have two problems. First, the interlayer channeling after the production of oil wells can cause watered-out reservoirs. Second, the fluid magrition after well cementing can usually cause the great danger. An origin of these problems is the isolation failure of cement-formation interface, and it has seriously restricted the effect and benefit of petroleum exploration and development [1-4]. The practice proves that the main pathway of fluid channeling is located in the cement-formation interface [5]. In other words, the cement sheath can be peeled off from the borehole wall so long as the mud cake exists. This will cause microcracks between cement sheath and borehole wall, which reduces the bonding strength of cement-formation interface and provides a path or channel for fluids (oil, gas and water) from the reservoir or formation [6, 7]. So the main factor that causes the isolation failure of cement-formation interface is the interface defects [2]. In order to solve this problem, the MTC (Mud to Cement) method was proposed in the early 1990s [8]. This method can achieve the integrated solidification and cementation of cement-formation interface (ISCCFI) combined

*Address correspondence to this author at the Petroleum Engineering Department, Faculty of Earth Resources, China University of Geosciences; No. 388, Lumo Road, Wuhan, Postcard: 430074 China;

Tel: +86-27-6784-8569; Fax: +86-27-6788-3051;

E-mail: gujun2199@126.com with multifunctional drilling fluids [9, 10]. However, it has been questioned by many scholars since 1994, because the MTC solidified body is brittle [11-13]. So, the MTC method can only be used in the well cementing of surface casing and intermediate casing of oil and gas well [14, 15].

In order to improve the bonding quality of cementformation interface effectively, a scientific concept of Mud Cake to Agglomerated Cake (MTA) was proposed [16]. It attempted to achieve the ISCCFI. The experimental evidences of ISCCFI with MTA method were obtained by mechanical evaluation, microstructural analysis and fluid dissolution test $[17,18]$. This method has been applied in 23 adjustment wells in Daqing, Shengli, and Henan oilfields in China. The applications show that this method has a remarkable effect [19, 20]. Based on DSC (differential scanning calorimetry) test, the kinetic models of ISCCFI with MTA method were established.

\section{EXPERIMENTAL}

\subsection{Experimental Material}

The mud cake modifier and forming agent of agglomerated cake are made in-house. The spacer is composed of 85 $\%$ tap water and $15 \%$ forming agent of agglomerated cake. The drilling fluid is the drilling and completion fluid from Henan oilfield in China with $1 \%-3 \%$ mud cake modifier added. The formula of the cement slurry is Class G cement with $0.4 \%$ dispersant and $46 \%$ tap water. 


\subsection{Sample Preparation}

The preparation method of experimental samples can refer to the reference [4]. The permeability and porosity of simulated wellbore (SWB) are $450 \times 10^{-3} \mu \mathrm{m}^{2}$ and $26 \%$ respectively, which simulate the reservoir properties of main bonding section in Henan oilfield. The DSC test samples (100 mg each share) are taken from the agglomerated cake at cement-formation interface of well-prepared SWB with a special tool, and put into the special seal-bags carefully.

\subsection{Measurement of DSC Curve}

The DSC curve is measured by Diamond Differential Scanning Calorimetry Analyzer from Platinum-Elmer Instruments (Shanghai) Co., Ltd. According to the temperature profiles of most oilfields in China, the heating rates with dynamic method are set at $5^{\circ} \mathrm{C} / \mathrm{min}, 10{ }^{\circ} \mathrm{C} / \mathrm{min}$ and 20 ${ }^{\circ} \mathrm{C} / \mathrm{min}$ respectively, and the temperatures range from $50{ }^{\circ} \mathrm{C}$ to $130{ }^{\circ} \mathrm{C}$. While based on the temperatures of most reservoirs in China, the temperatures with isothermal method are set at $50{ }^{\circ} \mathrm{C}, 75^{\circ} \mathrm{C}$ and $90^{\circ} \mathrm{C}$ respectively, and the temperature will keep constant after reach a setting one at $20^{\circ} \mathrm{C} / \mathrm{min}$.

\section{RESULTS AND ANALYSIS}

\subsection{Kinetic Analysis of ISCCFI with Dynamic Method}

The DSC curves adjusted by Origin software are showed in Fig. (1). Obviously, the DSC curves of various heating rates have two exothermic peaks. The temperature of the first exothermic peak ranges from $50{ }^{\circ} \mathrm{C}$ to $100{ }^{\circ} \mathrm{C}$, while the second exothermic peak ranges from $80^{\circ} \mathrm{C}$ to $140{ }^{\circ} \mathrm{C}$. The initial temperature $T_{\mathrm{i}}$, peak tip temperature $T_{\mathrm{p}}$ and final temperature $T_{\mathrm{f}}$ of reaction exothermic peak tend to be higher with the increase of heating rate $\beta$. The data from the first and second exothermic peak are listed in Tables $\mathbf{1}$ and $\mathbf{2}$ respectively.

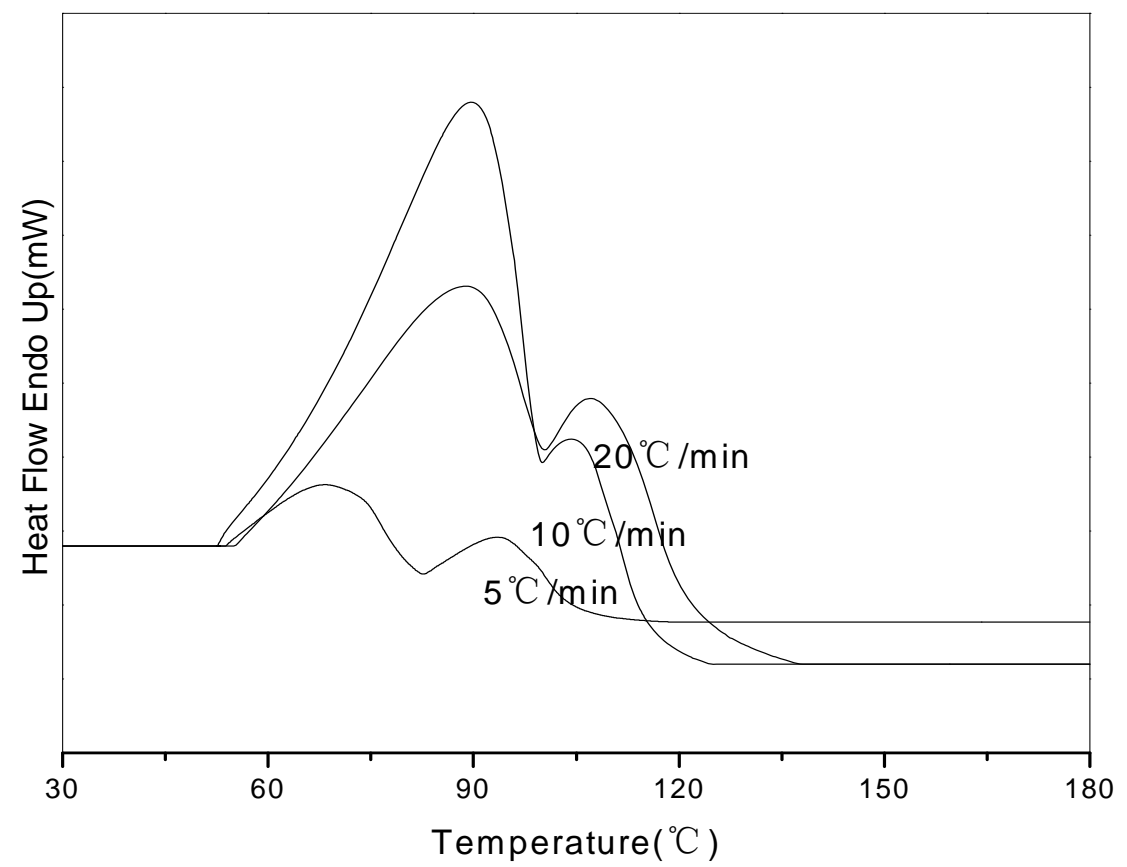

Fig. (1). DSC curves measured with dynamic method.

Table 1. Data from the First Exothermic Peak

\begin{tabular}{|c|c|c|c|c|c|c|}
\hline $\boldsymbol{B}\left({ }^{\circ} \mathbf{C} \cdot \mathbf{m i n}^{-1}\right)$ & $\boldsymbol{T}_{\mathbf{i}}(\mathbf{K})$ & $\boldsymbol{T}_{\mathbf{p}}(\mathbf{K})$ & $\boldsymbol{T}_{\mathrm{f}} / \mathbf{K}$ & $\mathbf{1} / \boldsymbol{T}_{\mathbf{p}}\left(\mathbf{1 0}^{\mathbf{3}} \mathbf{K}^{-\mathbf{1}}\right)$ & $\ln \left(\boldsymbol{\beta} / \boldsymbol{T}_{\mathbf{p}}^{2}\right)$ & $\ln \boldsymbol{\beta}$ \\
\hline \hline 5 & 327.05 & 341.61 & 355.82 & 2.927 & -10.058 & -9.609 \\
\hline 10 & 325.82 & 362.91 & 373.28 & 2.756 & -9.486 & 2.303 \\
\hline 20 & 328.46 & 362.07 & 373.46 & 2.762 & -8.788 & 2.996 \\
\hline
\end{tabular}

Table 2. Data from the Second Exothermic Peak

\begin{tabular}{|c|c|c|c|c|c|c|}
\hline $\boldsymbol{B}\left({ }^{(} \mathbf{C} \cdot \mathbf{m i n}^{-1}\right)$ & $\boldsymbol{T}_{\mathbf{i}}(\mathbf{K})$ & $\boldsymbol{T}_{\mathbf{p}} \mathbf{( K )}$ & $\boldsymbol{T}_{\mathbf{f}} / \mathbf{K}$ & $\mathbf{1} / \boldsymbol{T}_{\mathbf{p}}\left(\mathbf{1 0 ^ { 3 }} \mathbf{K}^{-\mathbf{1}}\right)$ & $\ln \left(\boldsymbol{\beta} / \boldsymbol{T}_{\mathbf{p}}{ }^{2}\right)$ & $\mathbf{I n} \boldsymbol{\beta}$ \\
\hline \hline 5 & 355.82 & 366.59 & 393.56 & 2.728 & -10.199 \\
\hline 10 & 373.28 & 377.44 & 397.65 & 2.649 & -9.564 \\
\hline 20 & 373.46 & 380.14 & 410.59 & 2.631 & -8.885 & 2.303 \\
\hline
\end{tabular}




\subsubsection{Determination of Solidification Temperature with Extrapolation}

The research shows that there is a linear relationship between the solidification reaction temperature and heating rate [21]. Thus, the solidification temperature of mud cake can be calculated with extrapolation. The results show that $T_{\mathrm{i}}, T_{\mathrm{p}}$ and $T_{\mathrm{f}}$ of the first exothermic peak are $53^{\circ} \mathrm{C}, 69^{\circ} \mathrm{C}$ and 83 ${ }^{\circ} \mathrm{C}$ respectively Fig. (2), and $T_{\mathrm{i}}, T_{\mathrm{p}}$ and $T_{\mathrm{f}}$ of the second exothermic peak are $83{ }^{\circ} \mathrm{C}, 92{ }^{\circ} \mathrm{C}$ and $114{ }^{\circ} \mathrm{C}$ respectively Fig. (3).

\subsubsection{Determination of Apparent Activation Energy in Solidification Reaction}

Kissinger pointed out that there was a certain mathematical relationship among the apparent activation energy $E_{\mathrm{a}}, T_{\mathrm{P}}$ and $\beta$ of solidification reaction [21]. Based on Kissinger Equation and data in Table 1, the relationship between $\ln \left(\beta / T_{\mathrm{P}}{ }^{2}\right)$ and $1 / T_{\mathrm{P}}$ from the first exothermic peak can be obtained by linear regression Fig. (4), and the fitting de- gree is 0.33706 .

According to the slope of fitting line in Fig. (4), $E_{\mathrm{a}} / R$ is $5.33912 \mathrm{~K}$, and $E_{\mathrm{a}}$ is $44.39 \times 10^{-3} \mathrm{~kJ} \cdot \mathrm{mol}^{-1}$. From the intercept of fitting line in Fig. (4), the natural logarithm of preexponential factor $\ln A_{\mathrm{i}}$ is 7.26 .

Similarly, based on Kissinger Equation and data in Table 2 , the relationship between $\ln \left(\beta / T_{\mathrm{P}}{ }^{2}\right)$ and $1 / T_{\mathrm{P}}$ from the second exothermic peak can be obtained by linear regression Fig. (5), and the fitting degree is 0.75241 .

According to the slope of fitting line in Fig. (5), $E_{\mathrm{a}} / R$ is $11.93005 \mathrm{~K}$, and $E_{\mathrm{a}}$ is $99.14 \times 10^{-3} \mathrm{~kJ} \cdot \mathrm{mol}^{-1}$. From the intercept of fitting line in Fig. (5), $\ln A_{\mathrm{i}}$ is 24.77.

\subsubsection{Determination of the Solidification Reaction Order}

Crane equation can be expressed as below [21]:

$\frac{d(\ln \beta)}{d\left(1 / T_{p}\right)}=-\left(\frac{E_{a}}{n R}+2 T_{p}\right)$

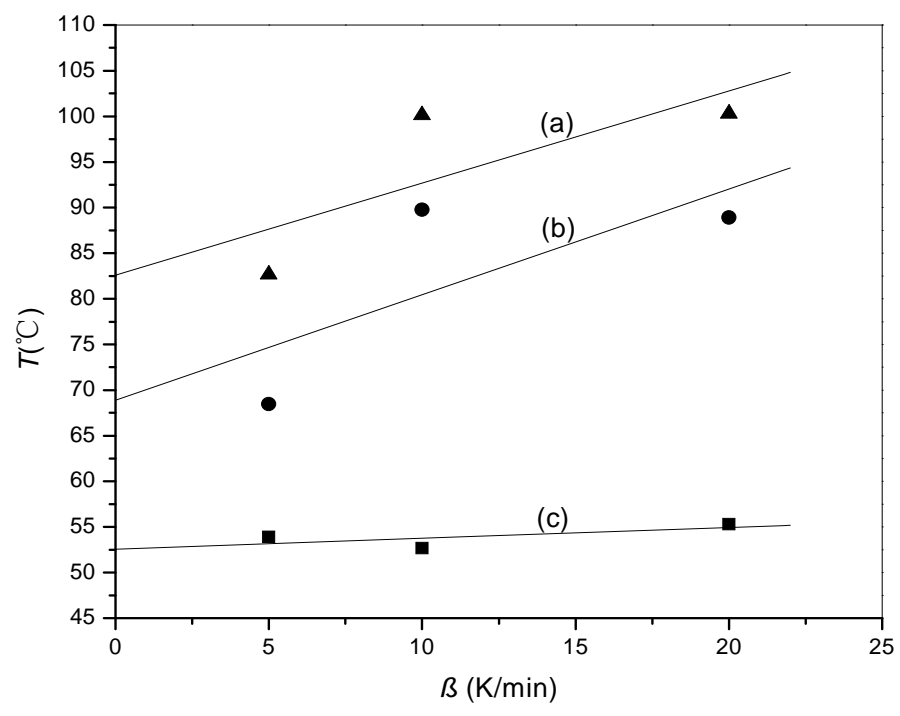

Fig. (2). Relationship between $T_{\mathrm{i}}, T_{\mathrm{p}}, T_{\mathrm{f}}$ and $\beta$ from the first exothermic peak [(a) $T_{\mathrm{f}}$, (b) $T_{\mathrm{p}}$, (c) $\left.T_{\mathrm{i}}\right]$.

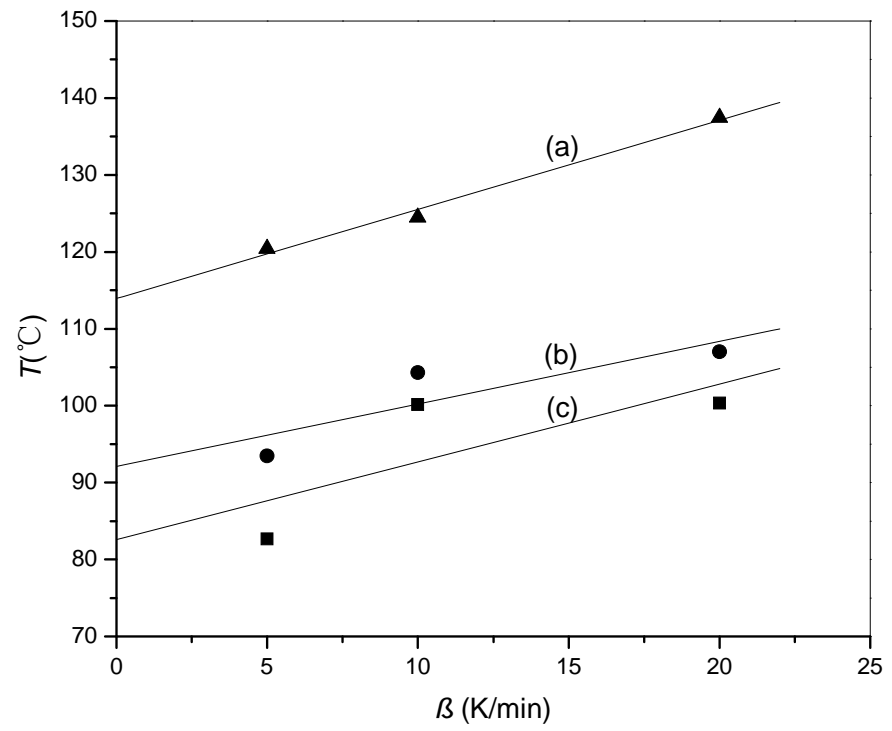

Fig. (3). Relationship between $T_{\mathrm{i}}, T_{\mathrm{p}}, T_{\mathrm{f}}$ and $\beta$ from the second exothermic peak [(a) $T_{\mathrm{f}}$, (b) $\left.T_{\mathrm{p}},(\mathrm{c}) T_{\mathrm{i}}\right]$. 


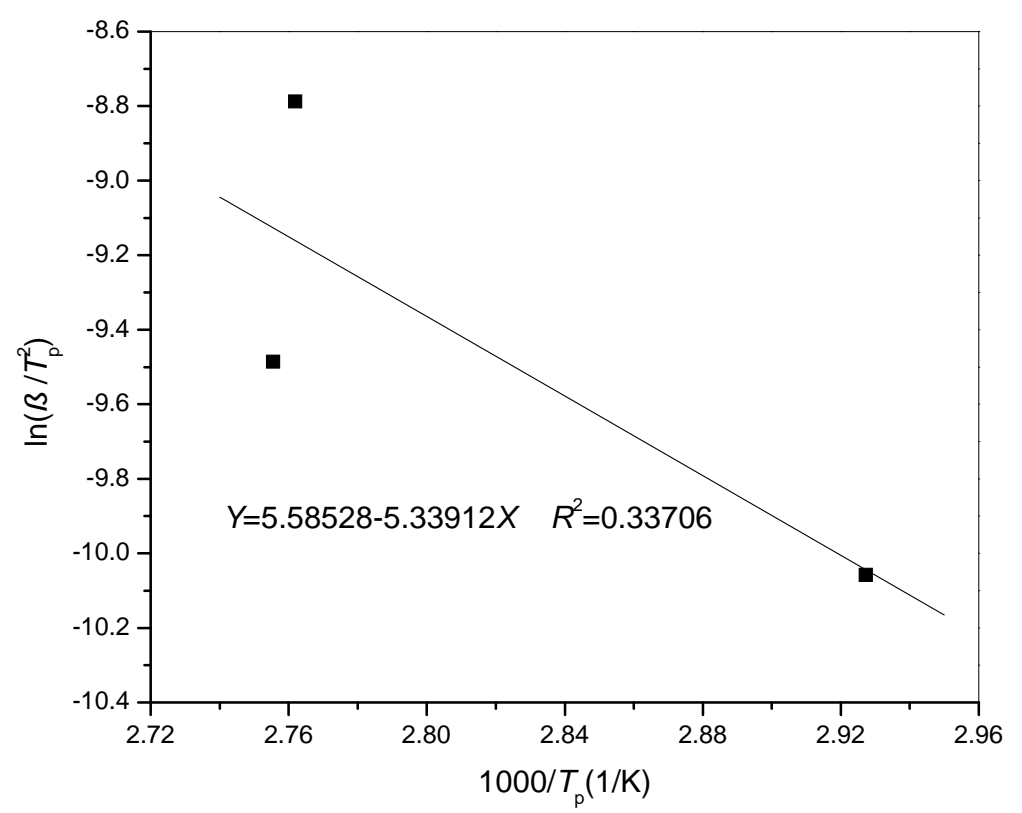

Fig. (4). Relationship between $\ln \left(\beta / T_{\mathrm{P}}{ }^{2}\right)$ and $1 / T_{\mathrm{P}} \times 10^{-3}$ from the first exothermic peak.

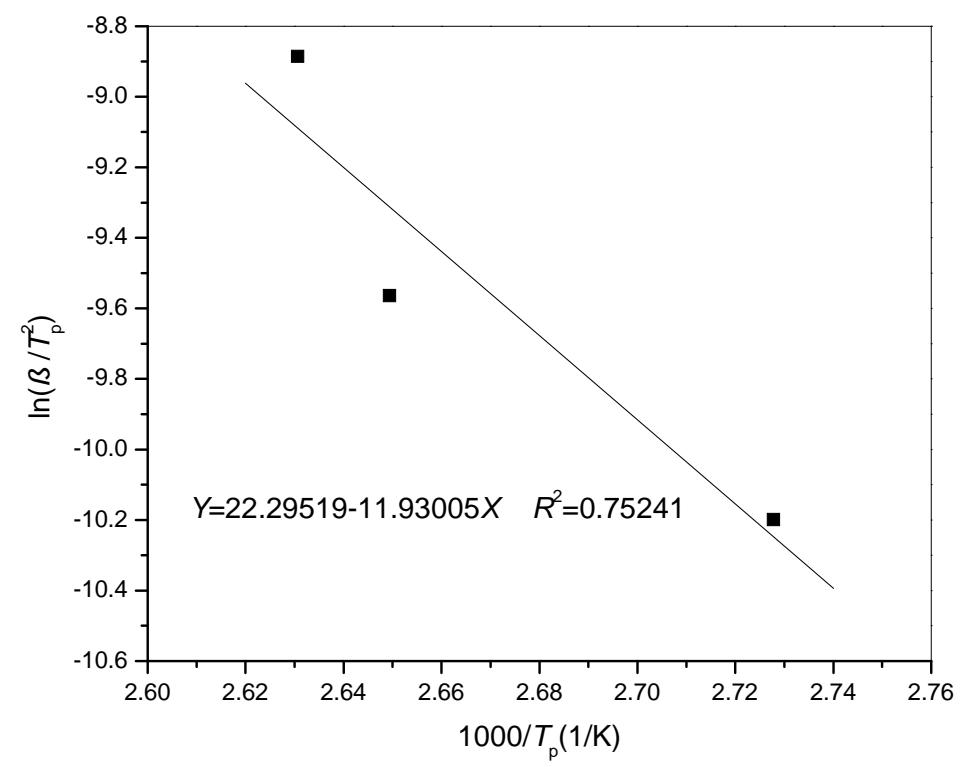

Fig. (5). Relationship between $\ln \left(\beta / T_{\mathrm{P}}{ }^{2}\right)$ and $1 / T_{\mathrm{P}} \times 10^{-3}$ from the second exothermic peak.

When $E_{\mathrm{a}} /(n R)$ is much bigger than $T_{\mathrm{p}}, 2 T_{\mathrm{p}}$ can be ignored in Eq. 1.

Substituting the relevant data above into Eq. 1, the calculation results show that the solidification reaction orders $n$ of the first and second exothermic peaks are 0.88 and 0.94 respectively. Thus, the reaction can be considered as a complex reaction.

\subsection{Kinetic Analysis of ISCCFI with Isothermal Method}

According to the analysis above with dynamic method, $T_{\mathrm{p}}$ 's of two exothermic peaks are $69{ }^{\circ} \mathrm{C}$ and $92{ }^{\circ} \mathrm{C}$ respectively. So, the experimental temperatures with isothermal method are selected at $50{ }^{\circ} \mathrm{C}, 75^{\circ} \mathrm{C}$ and $90^{\circ} \mathrm{C}$ respectively. The DSC curves at three different temperatures are showed in Fig. (6).

\subsubsection{Determination of Solidification Degree and Reaction Rate}

By measuring the heat generated in process of solidification reaction, the solidification kinetic parameters of mud cake with isothermal method can be calculated. The reaction heat varies with temperature and time $t$. In the process of reaction, the consumed amount of active functional groups stands for the extent of the reaction. By assuming that the heat evolved during curing is proportional to the extent of the reaction [22], the released heat is proportional to the consumed amount of active functional groups in process of solidification reaction. Based on this, the solidification degree $\alpha$ and reaction rate $d \alpha / d t$ in process of solidification reaction can be expressed as follows: 
$\alpha=\frac{\Delta H_{t}}{\Delta H_{0}}$

$\frac{d \alpha}{d t}=\frac{1}{\Delta H_{0}} \cdot \frac{d H}{d t}$

According to Eqs. 2 and 3, the relationship between $\alpha$ and $t$ at different experimental temperatures is illustrated in Fig. (7), and the relationship between $d \alpha / d t$ and $\alpha$ at different experimental temperatures is illustrated in Fig. (8).

From Fig. (7), within a certain solidification time, the higher the solidification temperature is, the higher $\alpha$. For a certain temperature, $\alpha$ increases quickly in initial reaction stage, but slowly after reaches 0.6 . At last, $\alpha$ keeps constant.
It is caused by the growth, branching and crosslinking of chain in the process of mud cake solidification. With the development of solidification reaction, the molecular weight and crosslinking density increase, while the fluidity of reaction molecular decreases, so $d \alpha / d t$ decreases.

From Fig. (8), at a certain temperature, $d \alpha / d t$ increases with $\alpha$ in the initial reaction stage. The maximum values of $d \alpha / d t$ at $50{ }^{\circ} \mathrm{C}, 75^{\circ} \mathrm{C}$ and $90^{\circ} \mathrm{C}$ are $0.09 \times 10^{-3} \mathrm{~s}^{-1}, 0.27 \times 10^{-3} \mathrm{~s}^{-}$ 1 and $0.51 \times 10^{-3} \mathrm{~s}^{-1}$ respectively.

\subsubsection{Determination of Reaction rate Function}

The solidification reaction of ISCCFI with MTA method can be described by the phenomenological model [23]:

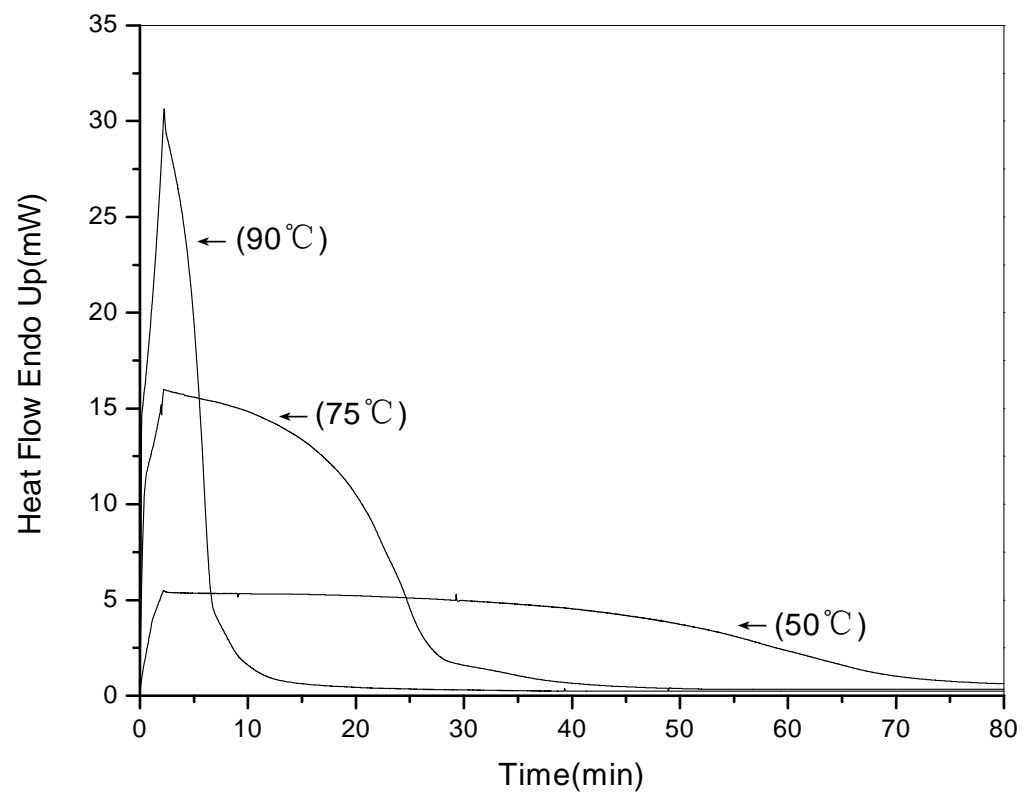

Fig. (6). DSC curves measured with isothermal method.

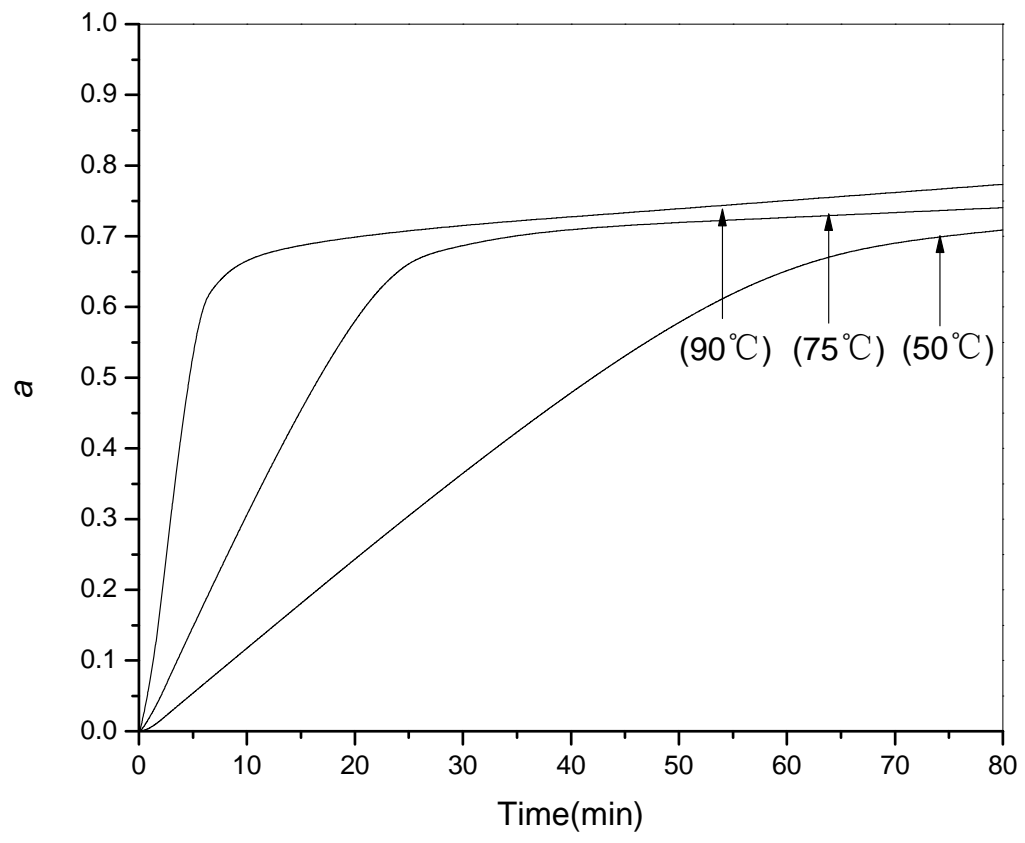

Fig. (7). Relationship between $\alpha$ and $t$ with isothermal method. 


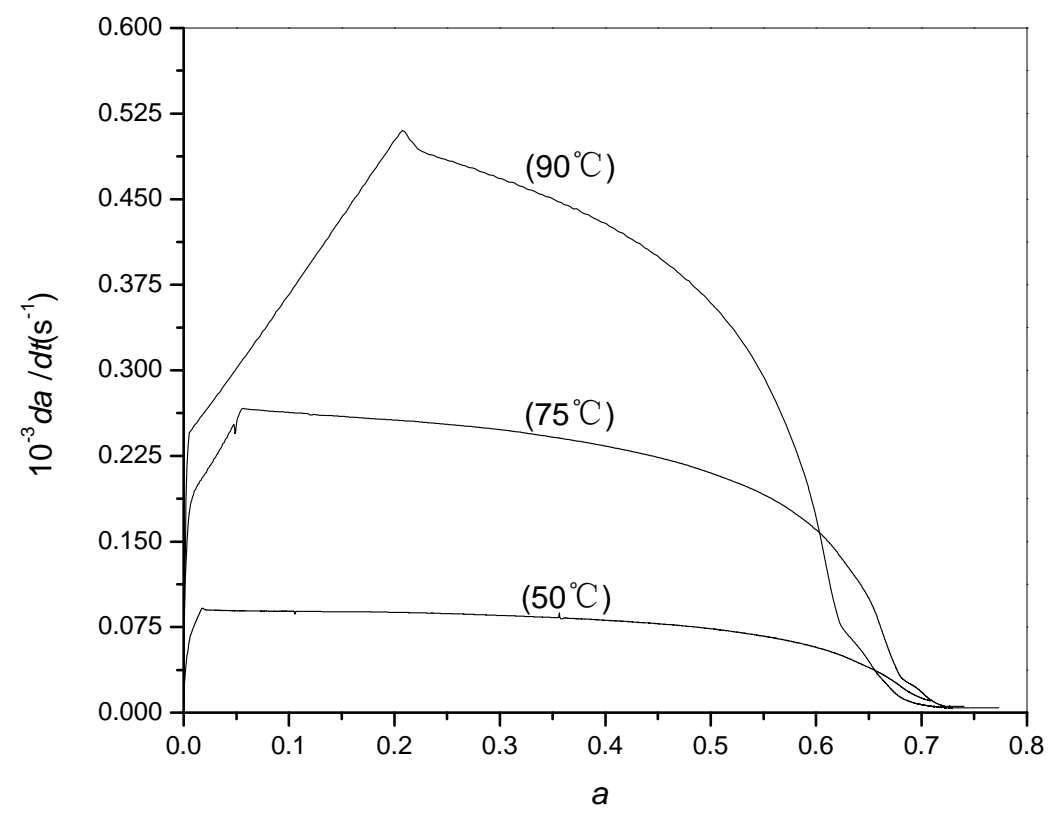

Fig. (8). Relationship between $d \alpha / d t$ and $\alpha$ with isothermal method.

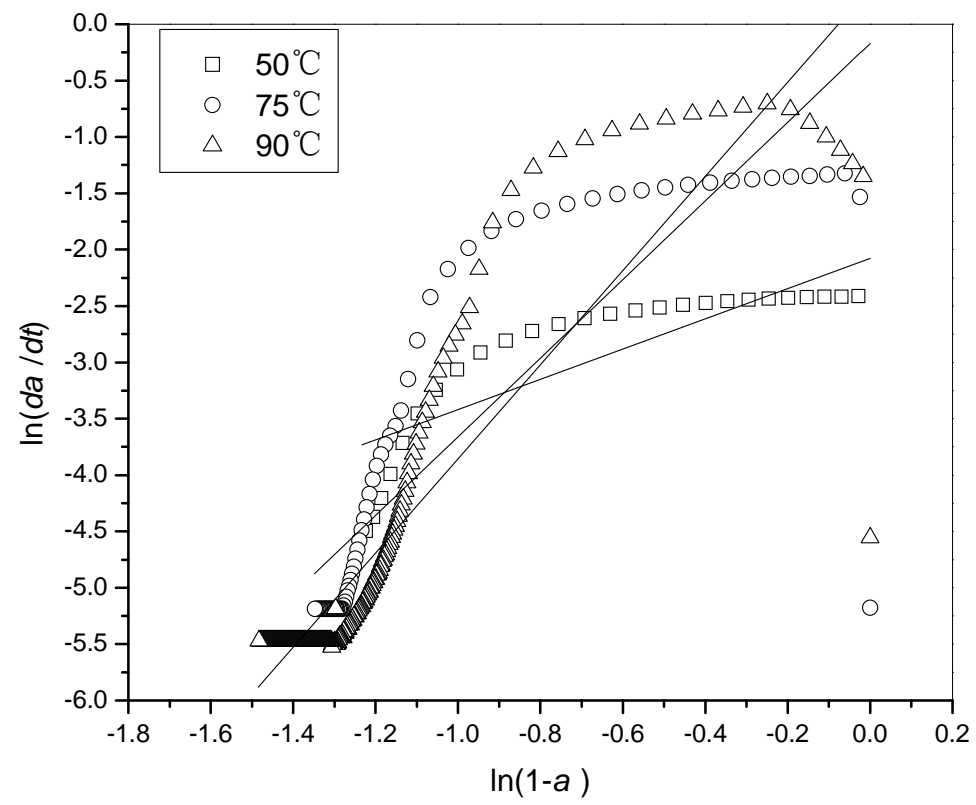

Fig. (9). Relationship between $\ln (d \alpha / d t)$ and $\ln (1-\alpha)$ with isothermal method.

$\frac{d \alpha}{d t}=\left(k_{2}+k_{3} \alpha^{m}\right)(1-\alpha)^{n}$

Considering the intercept of curve $(t=0)$ in Figures 7 and 8 as the initial reaction rate, $k_{2}$ in Eq. 4 can be calculated as follows:

$\left[\frac{d \alpha}{d t}\right]_{t=0}=k_{2}$

By taking natural logarithm on each side in Eq. 4, Eq. 4 is transformed into:

$\ln \left(\frac{d \alpha}{d t}\right)=\ln \left(k_{2}+k_{3} \alpha^{m}\right)+n \ln (1-\alpha)$
When $\alpha$ tends to be $1, \ln \left(k_{2}+k_{3} \alpha^{\mathrm{m}}\right)$ is considered as a constant, then $d \ln (d \alpha / d t) / d \ln (1-\alpha)$ is equal to the reaction order. Based on $\ln \left(\beta / T_{\mathrm{P}}{ }^{2}\right)$ and $1 / T_{\mathrm{P}}$, Fig. (9) can be obtained by regression analysis. The slope of regression curve is equal to $d \ln (d \alpha / d t) / d \ln (1-\alpha)$, then $n$ can be determined.

Eq. 6 can be written as the following style:

$\ln \left(\frac{d \alpha / d t}{(1-\alpha)^{n}}-k_{2}\right)=\ln k_{3}+m \ln \alpha$

Because $k_{2}$ and $n$ can be calculated by Eqs. 5 and 6 respectively, the relationship between $\ln \left[(d \alpha / d t) /(1-\alpha)^{n}-k_{2}\right]$ and $\ln \alpha$ can be obtained by regression analysis [Fig. (10)]. The reaction order $m$ and $k_{3}$ are calculated respectively by the slope and intercept of the curve. 
Based on $k_{2}$ and $k_{3}$, the activation energy and preexponential factor can be calculated by Arrhenius equation [23]:

$k_{i}=A_{i} \exp \left(-\frac{E_{a(i)}}{R T}\right)$

Eq. 8 can be transformed into the following style by taking natural logarithm on each side:

$\ln k_{i}=\ln A_{i}-\frac{E_{a(i)}}{R T}$

Based on $\ln k_{\mathrm{i}}$ and $1 / T$, Figs. (11) and (12) can be obtained. The equations in the figures are established by regression analysis. And the activation energy is obtained by the slope of the line, while the intercept is $\ln A_{\mathrm{i}}$.

From the figures and calculated data above, the kinetic parameters of solidification reaction with isothermal method are obtained (Table $\mathbf{3}$ ).

\subsubsection{Kinetic models of ISCCFI with MTA method}

Based on the analysis above, the kinetic models of ISCCFI with MTA method under three temperatures can be expressed as follows:

$$
\begin{aligned}
& \text { At } 50{ }^{\circ} \mathrm{C} \frac{d \alpha}{d t}=\left(0.833+0.149 \alpha^{0.16}\right)(1-\alpha)^{1.34} \\
& \text { At } 75{ }^{\circ} \mathrm{C} \frac{d \alpha}{d t}=\left(5.650+1.020 \alpha^{0.30}\right)(1-\alpha)^{3.49}
\end{aligned}
$$

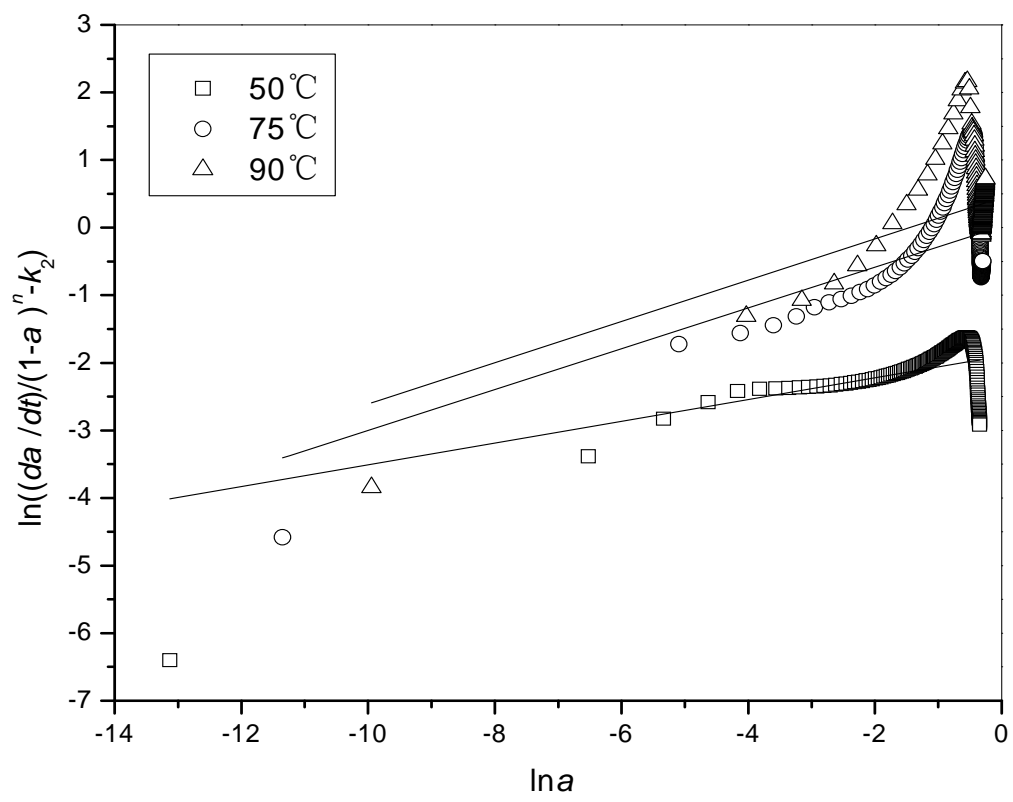

Fig. (10). Relationship between $\ln \left[(d \alpha / d t) /(1-\alpha)^{n}-k_{2}\right]$ and $\ln \alpha$ with isothermal method.

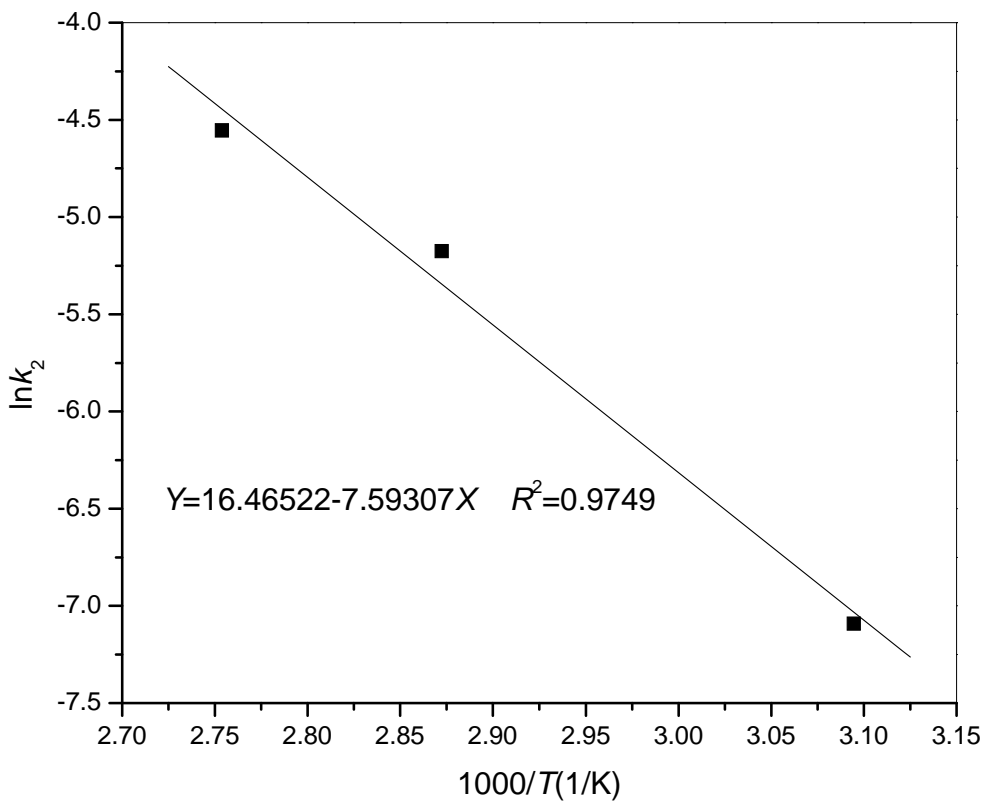

Fig. (11). Relationship between $\ln k_{2}$ and $1 / T$ with isothermal method. 


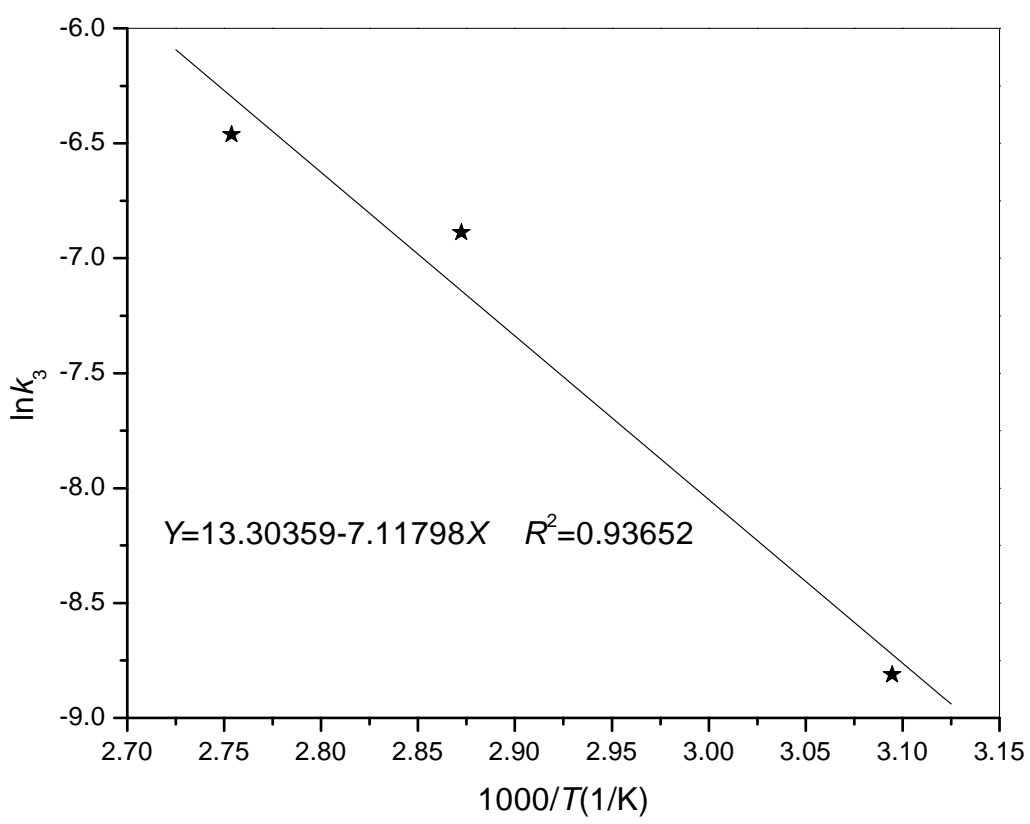

Fig. (12). Relationship between $\ln k_{3}$ and $1 / T$ with isothermal method.

Table 3. Kinetic Parameters Of Solidification Reaction with Isothermal Method

\begin{tabular}{|c|c|c|c|c|c|c|c|c|}
\hline$T\left({ }^{\circ} \mathbf{C}\right)$ & $k_{2}\left(10^{-3} \mathrm{~s}^{-1}\right)$ & $k_{3}\left(10^{-3} \mathrm{~s}^{-1}\right)$ & $m$ & $n$ & $\ln A_{1}$ & $\ln A_{2}$ & $E_{a 1}$ & $E_{02}$ \\
\hline 75 & 5.650 & 1.020 & 0.30 & 3.49 & \multirow[t]{2}{*}{16.49} & \multirow[t]{2}{*}{13.30} & \multirow[t]{2}{*}{63.13} & \multirow[t]{2}{*}{59.18} \\
\hline 90 & 10.530 & 1.561 & 0.31 & 4.18 & & & & \\
\hline
\end{tabular}

At $90{ }^{\circ} \mathrm{C} \frac{d \alpha}{d t}=\left(10.530+1.561 \alpha^{0.31}\right)(1-\alpha)^{4.18}$

\section{CONCLUSIONS}

There is a linear relationship between the solidification reaction temperature and heating rate of ISCCFI with MTA method. For the first exothermic peak, $T_{\mathrm{i}}, T_{\mathrm{p}}$ and $T_{\mathrm{f}}$ are 53 ${ }^{\circ} \mathrm{C}$, $69{ }^{\circ} \mathrm{C}$ and $83{ }^{\circ} \mathrm{C}$ respectively, $E_{\mathrm{a}}$ of solidification reaction is $44.39 \times 10^{-3} \mathrm{~kJ} \cdot \mathrm{mol}^{-1}, \ln A_{\mathrm{i}}$ is 7.26 , and the solidification reaction order is 0.88 . For the second exothermic peak, $T_{\mathrm{i}}, T_{\mathrm{p}}$ and $T_{\mathrm{f}}$ are $83{ }^{\circ} \mathrm{C}, 92{ }^{\circ} \mathrm{C}$ and $114{ }^{\circ} \mathrm{C}$ respectively, $E_{\mathrm{a}}$ of solidification reaction is $99.14 \times 10^{-3} \mathrm{~kJ} \cdot \mathrm{mol}^{-1}, \ln A_{\mathrm{i}}$ is 24.77 , the solidification reaction order is 0.94 . The maximum values of $d \alpha / d t$ at $50{ }^{\circ} \mathrm{C}, 75{ }^{\circ} \mathrm{C}$ and $90{ }^{\circ} \mathrm{C}$ are $0.09 \times 10^{-3} \mathrm{~s}^{-1}$, $0.27 \times 10^{-3} \mathrm{~s}^{-1}$ and $0.51 \times 10^{-3} \mathrm{~s}^{-1}$ respectively. The solidification reaction of ISCCFI with MTA method under different constant temperatures can be described by the phenomenological model. But, as the assumptions given in this paper, the result still have some limitations. So it is necessary to study further on ISCCFI in order to solve the isolation problem of cement-formation interface effectively.

\section{NOMENCLATURE}

$T_{\mathrm{i}} \quad=\quad$ Initial temperature ${ }^{\circ} \mathrm{C}$

$T_{\mathrm{P}} \quad=\quad$ Peak tip temperature ${ }^{\circ} \mathrm{C}$

$\begin{array}{lll}T_{\mathrm{f}} & = & \text { Final temperature }{ }^{\circ} \mathrm{C} \\ \beta & = & \text { Heating rate }{ }^{\circ} \mathrm{C} \cdot \mathrm{min}^{-1} \\ E_{\mathrm{a}} & = & \text { Apparent activation energy } \mathrm{kJ} \cdot \mathrm{mol}^{-1} \\ m, & = & n \text { Reaction order } \\ R & = & \text { Universal gas constant } 8.314 \times 10^{-3} \mathrm{~kJ} \cdot \mathrm{mol}^{-} \\ R^{2} & = & \text { Fitting degree } \\ \alpha & = & \text { Solidification degree } \\ d \alpha / d t & = & \text { Solidification reaction rate } \mathrm{s}^{-1} \\ \Delta H_{0} & = & \text { Maximum reaction heat measured } \mathrm{with} \\ H_{\mathrm{t}} & = & \text { isothermal method } \mathrm{J} \cdot \mathrm{g}^{-1} \\ t & = & \text { Reaction heat during constant time } \mathrm{J} \cdot \mathrm{g}^{-1} \\ T & = & \text { Time min } \\ k_{2}, k_{3}, k_{\mathrm{i}} & = & \text { Reaction rate constants } \\ E_{\mathrm{a}(\mathrm{i})} & = & \text { Activation energy } \\ A_{\mathrm{i}} & = & \text { Preexponential factor } \\ & \end{array}$

\section{CONFLICT OF INTEREST}

The authors confirm that this article content has no conflicts of interest. 


\section{ACKNOWLEDGEMENTS}

This study was financially supported by the National Natural Science Foundation of China (Nos. 51174180 and 40972103).

\section{REFERENCES}

[1] M.M. Hossain, and M.K. Rahman, "Numerical simulation of complex fracture growth during tight reservoir stimulation by hydraulic fracturing”. J. Petrol. Sci. Eng., vol. 60, pp. 86-104, 2008.

[2] J. Gu, W. Yang, W. Qin, Y. Zhang, and Y. Gao, "Evaluation method for isolation ability of cement-formation interface". Acta Petrolei Sin., vol. 29, pp. 451-454, 2008.

[3] G. Zhang, and M. Chen, "Dynamic fracture propagation in hydraulic re-fracturing”. J. Petrol. Sci. Eng., vol. 70, pp. 266-272, 2010.

[4] J. Gu, B. Wang, and B. Yang, "The influences of interface missing and formation property on shearing strength at cement-formation interface”. Petrol. Sci. Technol., vol. 29, pp. 633-639, 2011.

[5] L. Liu, Z. Ren, G. Hu, and X. Cui, "Research and application of cold heavy oil production with sand technology”. J. Northwest. Univ. (Nat. Sci. Edi.), vol. 38, pp. 290-294, 2008.

[6] L. Zhao, X. Meng, and H. Du, "Bond properties of the interface between drilling cutting oil well cement”. J. Daqing. Petrol. Inst., vol. 20, 90-93, 1996.

[7] H.K.J. Ladva, B. Craster, T.G.J. Jones, G. Goldsmith, and D. Scott, "The cement-to-formation interface in zonal isolation". J. Petrol.Technol., vol. 57, pp. 41-42, 44, 2005.

[8] E.B. Nelson, Well Cementing. Schlumberger: USA, 1990.

[9] J. Hou, and Z. Liu, "Synthesizing dispersant for MTC design and its effect on slurry rheology”. SPE . Drill Completion, vol. 15, pp. 31-36, 2000

[10] R. Wang, L. Jiang, and Y.Bu, "Experimental study on hydration mechanism of slag MTC”. Acta Petrolei Sin., vol. 29, pp. 442-446, 2008.

[11] Z. Peng, Y. He, and C. Liu, "Basic causes analysis of cracking of MTC solidified body with cinder”. Nat. Gas. Ind., vol.25, pp. 7274, 2005.
[12] H. Huang, Y. Bu, and H. Tian, "Bonding strength experiment of mud to cement fluid on the second interface". J. China Univ. Petrol. (Nat. Sci. Edi.), vol.30, pp. 46-50, 2006.

[13] E.B. Nelson, and D. Guillot, Well Cementing $2^{\text {nd }}$ ed. Schlumberger: USA, 2006.

[14] Z. Xiao, M. Wu, and M. Xu, "The induced mechanism of crystal during hydratie of blast-furnace slag”. Acta Petrolei Sin., vol.19, pp. 117-121, 1998

[15] R. Sweatman, Well Cementing. Gulf Publishing Company: USA, 2010.

[16] J. Gu, "Problem of the cement-formation interface and scientific conception of mud cake to agglomerated cake”. J. Oil Gas. Technol., vol. 19, pp. 117-121, 2009.

[17] J. Gu, and W. Qin, "Experimental study on integrated solidification and cementation of cement-formation interface based on Mud Cake to Agglomerated Cake (MTA) method”. Petrol. Explor. Dev., vol. 37, pp. 226-231, 2010.

[18] J. Gu, W. Yang, Y. Zhang, Y. Gao, X. Liu, and T. Li, “Association between tuff diagenesis and mud cake to agglomerated cake (MTA) at cement-formati on interface”. J. China Univ. Petrol. (Nat. Sci. Edi.), vol. 35, pp. 64-68, 73, 2011.

[19] J. Gu, Y. Yang, L. Dong, P. Zhong, and H. Zhang, "Technical principle of integrated solidification and cementation at cementformation interface with Mud Cake to Agglomerated Cake (MTA) method and its oilfield application”. Adv. Mater. Res., vol. 236238, pp. 2864-2867, 2011.

[20] J. Gu, X. Li, H. Liu, Y. Zhang, and Y. Gao, "Laboratory evaluation and application of new materials based on Mud Cake to Agglomerated Cake (MTA) method”. Adv. Mater. Res., vol. 148-149, pp. 449-452, 2011.

[21] W. Lei, Z. Ling, Z. Ju, L. Zhu, and D. Zai, “Establishment of the kinetics equation of the curing reaction between $\mathrm{CaCO}_{3}$ particles and UP resin by dynamic DSC”. J. Nanjing Foreign Univ. (Nat. Sci. Ed.), vol. 27, pp. 48-50, 2003.

[22] M. Sultania, J.S.P. Rai, and D. Srivastava, "Modeling and simulation of curing kinetics for the cardanol-based vinyl ester resin by means of non-isothermal DSC measurements". Mater. Chem. Phys., vol. 132, pp. 180-186, 2012.

[23] X. Dai, J. Xiao, J. Zeng, J. Liu, C. Yin, and Z. Liu, "Curing kinetics of epoxy resin for RFI process using isothermal DSC”. Acta Mater Compos. Sin., vol. 25, pp. 18-23, 2008.

Received: January 23, 2013

Revised: April 15, 2013

Accepted: May 25, 2013

(C) Gu et al.; Licensee Bentham Open.

This is an open access article licensed under the terms of the Creative Commons Attribution Non-Commercial License (http://creativecommons.org/licenses/ by-nc/3.0/) which permits unrestricted, non-commercial use, distribution and reproduction in any medium, provided the work is properly cited. 